\title{
Preschoolers' extension of novel words to animals and artifacts*
}

\author{
SUSAN A. GRAHAM, ANDREA N. WELDER, \\ BEVERLEY A. MERRIFIELD AND JARED M. J. BERMAN \\ University of Calgary
}

(Received I9 Fune 2008 -Revised 24 December 2008 -First published online 30 October 2009)

\begin{abstract}
We examined whether preschoolers' ontological knowledge would influence lexical extension. In Experiment I, four-year-olds were presented with a novel label for either an object with eyes described as an animal, or the same object without eyes described as a tool. In the animal condition, children extended the label to similar-shaped objects, whereas in the tool condition, children extended the label to similar-function objects. In Experiment 2, when four-year-olds were presented with objects with eyes described as tools, they extended the label on the basis of shared function. These experiments suggest that preschoolers' conceptual knowledge guides their lexical extension.
\end{abstract}

In recent years, a lively debate between two particular accounts of word learning has emerged in the literature. Specifically, one account posits that the categories that underlie young children's object labels reflect their attention to correlations between salient perceptual properties (e.g. Colunga \& Smith, 2008; Landau, Smith \& Jones, I988). A competing account

[*] This research was supported by funding from NSERC of Canada, the University of Calgary and the Canada Research Chairs program awarded to the first author. We thank the parents, children and adults who participated in the studies as well as the staff at participating preschools and daycares in the Calgary area. Jennifer Storms, Tamara Demke and Cari Kilbreath provided us with assistance with this research. We thank Amy Booth, Diane Poulin-Dubois, Geoffrey Hall and an anonymous reviewer for their helpful comments on a previous version of this manuscript. Some of these data were presented at the annual meeting of the Canadian Society for Brain, Behaviour and Cognitive Science, Ottawa, June, I 998 and at the biennial meeting of the Society for Research in Child Development, Albuquerque, NM, April, I 999. Address for correspondence: S. A. Graham, Department of Psychology, University of Calgary, 2500 University Dr. NW, Calgary, $\mathrm{AB} \mathrm{T}_{2} \mathrm{~N}_{\text {IN }} 4$ Canada. fax: 403-282-8249. e-mail: grahams@ucalgary.ca 
suggests children's underlying conceptual knowledge guides their word learning (e.g. Bloom, 2000; Gelman, 2003). In these experiments, we examined whether preschoolers' ontological knowledge guided their attention to function versus shape when extending novel object labels to novel animals and artifacts.

Before they reach preschool age, children have a well-developed understanding of animal and artifact categories (e.g. Gelman \& Wellman, I99 I ; Rakison \& Poulin-Dubois, 200I). Many researchers have argued that these categories are based on children's conceptual knowledge or naive theories, and thus encompass more than perceptual information (Bloom, 2000; Gelman, 2003). With reference to word learning, then, it follows that children's knowledge about animals and artifacts should guide their decisions about which properties are relevant to a given category, and hence which properties to focus on for lexical extension. In support of this notion, studies have demonstrated that children's categorization and naming decisions are influenced by a conceptual distinction between animals and artifacts (e.g. Booth \& Waxman, 2002; Booth, Waxman \& Huang, 2005).

According to an alternative perspective, the Attentional Learning Account (ALA), word learning is guided by associationist mechanisms whereby children detect recurrent correlations between perceptual properties of objects and types of words present in the natural input (e.g. Samuelson \& Smith, I999; 2000; Smith, Jones \& Landau, I996; Smith \& Samuelson, 2006). In this view, children come to associate specific perceptual features with words. These perceptually based associations are then evoked automatically in the context of word learning without accessing any conceptual knowledge. For example, Jones and colleagues found that placing animacy cues (eyes or shoes) on novel objects led three-year-olds to emphasize shape and texture when extending novel count nouns. When animacy cues were not present, children relied exclusively on shape to extend the labels (Jones $\&$ Smith, I998; 2002). Jones and colleagues interpret these findings as demonstrating that preschoolers have learned a correlation between eyes and object texture and shape that is activated in a naming context.

Disentangling these two accounts can be challenging, as research findings can be interpreted by both accounts. That is, evidence for particular patterns of lexical extension in the presence of specific object cues (e.g. eyes) may be construed as resulting from automatic associations or from the ability to recruit conceptual information (for discussions see Booth \& Waxman, 2008; Colunga \& Smith, 2008; Gelman, 2003). For example, in Jones and colleagues' studies, it is possible that animacy cues led children to treat objects as meaningful representations of animals. Thus, the use of broader word extension criteria (i.e. texture and shape) may have been driven by an understanding of animal categories, rather than solely by contextually cued attention. 
Recent research conducted by Booth \& Waxman (2002) has directly addressed the influence of perceptual and conceptual information about ontological kind on three-year-olds' word extensions. They presented children with novel objects that were described either as animates or artifacts without any distinguishing perceptual features. When three-year-olds were presented with objects described as animate kinds, both shape and texture guided children's lexical extensions. However, when the same objects were described as artifact kinds, only shape guided their lexical extension. In a second study, when children were presented with conflicting perceptual and conceptual information about objects (i.e. objects with eyes were described as artifacts), preschoolers generalized the novel label on the basis of shape, demonstrating that the differential performance in lexical extension could not be due to attention to perceptual features. More recently, Booth et al. (2005) demonstrated that even two-year-olds will extend novel words differentially as a function of the category of the object being labeled. Thus, these studies demonstrate that animacy/artifact cues provided preschoolers with access to more conceptually based knowledge regarding ontological kind which then guided their lexical acquisition (see Smith \& Samuelson (2006) for a counter-argument).

In these experiments, we pursued the question of whether children's knowledge about animal and artifact categories influences their lexical extension. In particular, we examined whether depicting a novel object as either an animal or an artifact would lead preschoolers to apply different word extension criteria to similar looking or similar functioning novel objects. In Experiment I, we presented children with CONSISTENT perceptual and conceptual information about ontological kind. In Experiment 2, we presented children with CONFLICTING perceptual and conceptual information about ontological kind.

\section{EXPERIMENT I}

In Experiment I, we examined whether young four-year-olds would differentially extend a label to objects with or without animacy cues on the basis of similar shape or similar function. Children were taught a label for a target novel object which could perform a particular function. For one group, the object did not have any animacy cues and was described as a tool (tool condition). For a second group, the object had animacy cues (eyes) and was described as an animal (animal condition). For both groups, the object's appearance was described and its function (the ability to hold a ball) was demonstrated. We chose the ability to hold a ball as the target function as both animals and artifacts could perform this function. Children were then presented with pairs of test objects that varied in overall appearance, 
the ability to perform the function, or both, and were asked to extend a novel label. ${ }^{1}$

We expected that children's knowledge about animal and artifact categories would lead them to extend the label on the basis of the most relevant property for each category, given the properties available. Thus, when presented with the choice between shape and function similarity, we predicted that children would attend to object function when extending a novel noun to objects described as tools, given their understanding of the importance of function for defining artifact categories and research demonstrating that children often favor function over shape to label artifacts (e.g. Asher \& Kemler Nelson, 2008; Kemler Nelson, I999). In contrast, we predicted that children would attend to overall shape for the objects described as animals. In this experiment, texture was held constant across all objects, and thus shape was the best available cue for word extension in the animal group.

\section{METHOD}

\section{Participants}

Sixty-four four-year-olds ( 32 boys and 32 girls) were randomly assigned to one of two conditions: animal $(n=32, M=4 ; \mathrm{I}, S D=2 \cdot 9$ months) and tool ( $n=32, M=4$; I years, $S D=3.6$ months).

\section{Stimuli}

The test objects consisted of two sets of novel objects: animals and tools (see Figure I). Forty adults rated either the shape or the functional similarity of a series of test objects to a target object for either the animal or the tool set. The test objects varied in shape, functionality or both relative to a target object. The target and test objects in each set were identical except that all objects in the animal set had plastic eyes glued on them. Raters used a Likert-type scale (ranging from I-not at all similar to 7-very similar). Participants were told to focus solely on similarity in overall shape or in functionality, and that any other sources of similarity between the objects and the target object should be ignored. Only participants who rated functional similarity were told that the function of the target object was to hold the ball.

Based on the mean ratings of the shape similarity and functional similarity to the target object, four objects from each set were chosen for use in the experiment. Each set included a target object, a similar

[I] We focused on four-year-olds in these studies as pilot work indicated that younger children had difficulty with the term 'tool'.

$$
9 \text { I } 6
$$




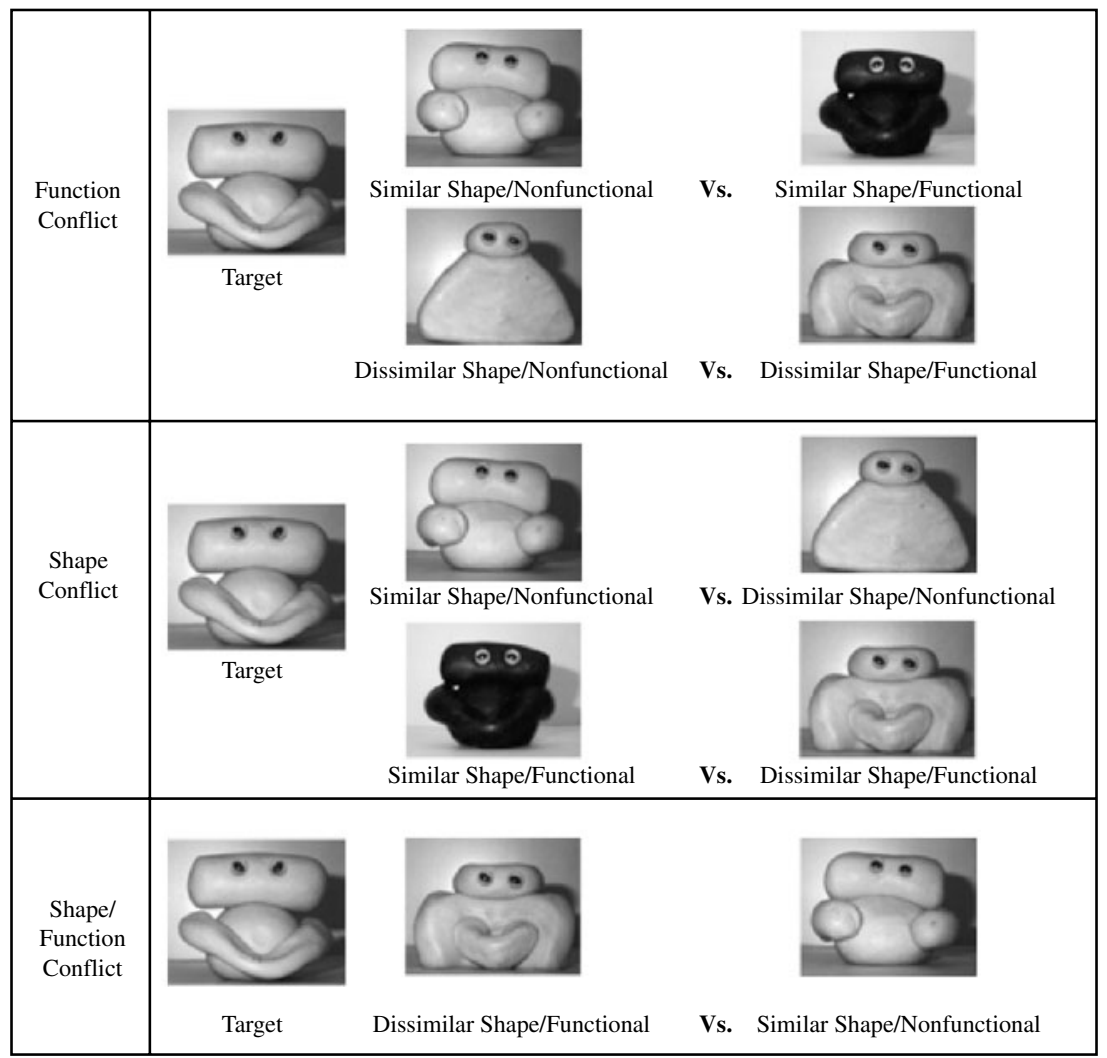

Fig. I. Conflict trials for animacy condition (NOTE: tool condition exactly the same without animacy cues (eyes)).

shape/functional object, a similar shape/non-functional object, a dissimilar shape/non-functional object and a dissimilar shape/functional object. In order to ensure that participants would not assume that the similar shape/ functional object was simply a replica of the target object, it differed in color from the target. Adults rated the similar shape and dissimilar shape objects significantly different from one another (all $p s<0.05$ ). Similarly, they rated the functional objects significantly higher in functionality than the nonfunctional objects $(p s<0.05)$. Shape and function ratings for the animal set and the tool set on the four test objects were not significantly different $(p s>0.05)$. Thus, ratings confirmed that the test objects designed to be similar in shape or function were indeed more similar to the target object than the objects designed to be dissimilar in shape or function. Furthermore, the animal and tool objects were not rated significantly differently, 
indicating that the two sets of objects were generally equivalent in shape and functionality.

\section{Procedure}

Testing began with warm-up trials using familiar animate and inanimate objects designed to acquaint children with the forced-choice procedure to be used on test trials and to eliminate any yes-no biases. These trials were followed by pretest questions during which the experimenter introduced children to either a teddy bear (animal condition) or a teaspoon (tool condition). She then instructed them as follows: "This is a kind of animal (tool). It can eat and sleep (pick up cereal and jello). What are some other animals (tools)?" Any appropriate animal or tool response other than teddy bear or spoon was acceptable. If children did not provide an acceptable response, she asked them a series of four questions: (I) "Is a cow an animal (tool)?" (2) "Is a hammer an animal (a tool)?" (3) "Is a dog an animal (a tool)?" (4) "Is a screwdriver an animal (a tool)?" Only those children who answered all four questions correctly continued with testing.

On the test trials, the experimenter presented children with the target object, labeled it with a novel count noun ("This is a rompel") and introduced it as a novel animal or a novel tool ("A rompel is a special kind of animal (tool)"). She then described the appearance ("See what a rompel looks like? It has a rounded bottom. It has arms (a tube) across the front.") and the function of the target object ("See what a rompel can do? It can hold a ball."'). The order in which appearance and functional ability were described was counterbalanced across children.

After introducing the target object, the experimenter administered the word extension trials. The test objects were paired in eight trials presented in a different random order for each child. There were three types of conflict trials and two control trials (see Figure I): (I) Functional conflicts: on two trials, the object's shape similarity to the target object was equated between both objects but one object was functional and one was not; (2) Shape conflicts: on another two trials, the object's ability to function or not function like the target object was equated between the two objects but one object was similar in shape to the target object and one object was dissimilar in shape; (3) Shape/Function conflicts: these were the two major trials of interest where the functional alternative was dissimilar in shape to the target object and the non-functional alternative was similar in appearance to the target object; (4) Control trials: on one control trial, a replica of the target object was paired with either an elephant (for the animal condition) or a shoe (for the tool condition). On a second control trial, a replica of the target object was paired with the dissimilar/non-functional object. These trials were used to ensure that children understood the task.

$$
9 \text { I } 8
$$


The same procedure was followed for each word extension trial: two test objects were placed to each side and in front of the target object and children were asked to extend the novel label ("Show me another rompel"). Once the child made a choice, the experimenter pointed to the object not chosen and asked, "Could this also be a rompel?".

\section{RESULTS}

\section{Control trials}

All children extended the novel word to the replica of the target object, rather than to the elephant or shoe. When a replica of the target object was paired with the dissimilar/non-functional object, $88 \%$ of the children chose the replica of the target object. These results indicate that children understood the task demands. ${ }^{2}$

\section{Forced choice selections}

In order to examine whether ontological kind influenced children's lexical extension across the various types of conflict trials presented, we compared the number of children choosing each particular object on the different conflict trials as a function of group, using chi-square analyses (see Table I). These analyses indicated that object selections differed across groups only on the shape-function conflict trials. On these trials, the majority of children in the animal group chose the same shape-non-functional object as the referent of the novel word while the majority of children in the tool group chose the dissimilar shape-functional object $(p s<0 \cdot 0 \mathrm{I})$.

\section{Weighted choices}

In these analyses, we examined the extent to which children restricted the label exclusively the same-shape or same-function objects. To address this issue, we adopted a weighted scoring scheme that took into account both the choices made on the forced-choice trial and the yes-no answers that followed. Children were assigned a weighted value according to: (I) their first choice on each trial; and (2) whether they responded yes or no to the object they did not choose. A score of $\mathrm{I}$ indicated a consistent use of function; a score of 0.5 indicated no reliable use of shape or function (i.e. inconsistent responding) on the Shape Conflict I, Function Conflict I and Shape-Function conflict trials or null responding on the Shape Conflict 2

[2] The same word extension patterns described in the subsequent sections was found both when we included and when we eliminated those children who did not correctly choose the target object on the control trials. 
GRAHAM $E T A L$.

TABLE I. Number of children choosing each object as a function of trial type and group

\begin{tabular}{|c|c|c|c|}
\hline Trial type & Group & Number of chilc & choosing object \\
\hline \multirow[t]{4}{*}{$\begin{array}{l}\text { Function } \\
\text { conflict } I\end{array}$} & & $\begin{array}{l}\text { Similar shape- } \\
\text { functional }\end{array}$ & $\begin{array}{l}\text { Similar shape-non- } \\
\text { functional }\end{array}$ \\
\hline & Animals $(n=32)$ & 29 & 3 \\
\hline & Tools $(n=32)$ & 30 & 2 \\
\hline & Tools-eyes $(n=20)$ & I7 & 3 \\
\hline \multirow[t]{4}{*}{$\begin{array}{l}\text { Function } \\
\text { conflict } 2\end{array}$} & & $\begin{array}{c}\text { Dissimilar shape- } \\
\text { functional }\end{array}$ & $\begin{array}{c}\text { Dissimilar shape- } \\
\text { non-functional }\end{array}$ \\
\hline & Animals $(n=32)$ & 28 & 4 \\
\hline & Tools $(n=32)$ & 24 & 8 \\
\hline & Tools-eyes $(n=20)$ & I6 & 4 \\
\hline \multirow[t]{4}{*}{$\begin{array}{l}\text { Shape } \\
\text { conflict I }\end{array}$} & & $\begin{array}{l}\text { Similar shape- } \\
\text { functional }\end{array}$ & $\begin{array}{l}\text { Dissimilar shape- } \\
\text { functional }\end{array}$ \\
\hline & Animals $(n=32)$ & 29 & 3 \\
\hline & Tools $(n=32)$ & 23 & 9 \\
\hline & Tools-eyes $(n=20)$ & I 4 & 6 \\
\hline \multirow[t]{4}{*}{$\begin{array}{l}\text { Shape } \\
\text { conflict } 2\end{array}$} & & $\begin{array}{l}\text { Similar shape-non- } \\
\text { functional }\end{array}$ & $\begin{array}{c}\text { Dissimilar shape- } \\
\text { non-functional }\end{array}$ \\
\hline & Animals $(n=32)$ & 26 & 6 \\
\hline & Tools $(n=32)$ & I 8 & I 2 \\
\hline & Tools-eyes $(n=20)$ & I 4 & 5 \\
\hline \multirow[t]{4}{*}{$\begin{array}{l}\text { Shape-function } \\
\text { conflict } I^{*}\end{array}$} & & $\begin{array}{l}\text { Similar shape-non- } \\
\text { functional }\end{array}$ & $\begin{array}{l}\text { Dissimilar shape- } \\
\text { functional }\end{array}$ \\
\hline & Animals $(n=32)$ & 23 & 9 \\
\hline & Tools $(n=32)$ & IO & 22 \\
\hline & Tools-eyes $(n=20)$ & 9 & I I \\
\hline \multirow[t]{4}{*}{$\begin{array}{l}\text { Shape-function } \\
\text { conflict } 2^{* *}\end{array}$} & & $\begin{array}{l}\text { Similar shape-non- } \\
\text { functional }\end{array}$ & $\begin{array}{l}\text { Dissimilar shape- } \\
\text { functional }\end{array}$ \\
\hline & Animals $(n=32)$ & 25 & 7 \\
\hline & Tools $(n=32)$ & 12 & 20 \\
\hline & Tools-eyes $(n=20)$ & 8 & I 2 \\
\hline
\end{tabular}

* Chi-square indicates significant group differences $\left(\chi^{2}(2)=\mathrm{I} 0.82, p<0.0 \mathrm{I}\right)$.

** Chi-square indicates significant group differences $\left(\chi^{2}(2)=12 \cdot 25, p<0 \cdot 0 \mathrm{I}\right)$.

and Function Conflict 2 trials; and finally, a score of $\mathrm{o}$ indicated a consistent use of shape (see Table 2 for further details on how the scheme applied to each conflict trial).

Function conflict and shape conflict trials. See Figure 2 for weighted scores. On both function conflict trials, children in the animal condition and in the tool condition did not differ significantly in their weighting of 


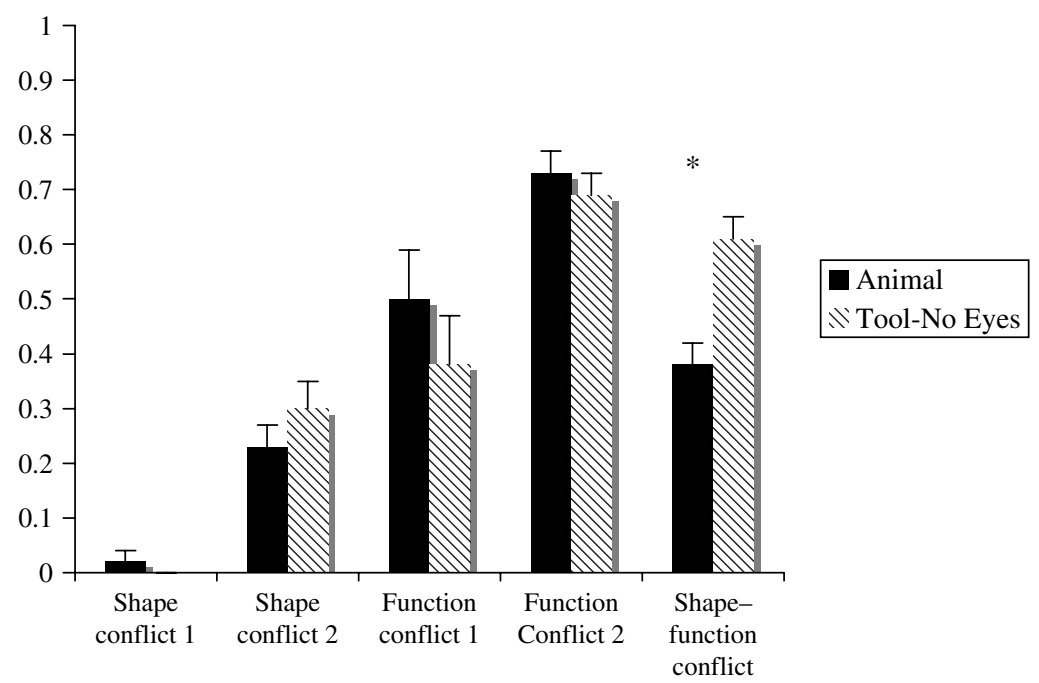

Fig. 2. Experiment $\mathrm{I}$ : Weighted choices as a function of condition and trial type. NOTE: Scores closer to I indicate weighing of function; scores closer to $\circ$ indicate weighing of shape.

* Animal condition significantly different from both tool conditions $(p<0.05)$.

function or shape, $p s>0.32$. Similarly, on the two shape-conflict trials, children in the animal condition and in the tool condition did not differ significantly in their weighting of function or shape, $p s>0.30$.

Shape/Function conflict trials. As the functional alternative was dissimilar in shape to the target object and the non-functional alternative was similar in appearance to the target object, these trials provided a stringent test of differential attention to shape and function for artifacts and animals. Children were remarkably consistent in their performance across these trials. That is, $84 \%$ of children in the animal group and $84 \%$ in the tool group responded identically on the two shape-conflict trials. As such, we averaged responding across the two trials. Analysis indicated that children in the tool condition weighted function significantly more than four-yearolds in the animal condition $(t(62)=3.57, d=0.9 \mathrm{I}, p<0.00 \mathrm{I})$.

\section{DISCUSSION}

When one property was eliminated as a cue for word extension (i.e. on the function-conflict and shape-conflict trials), ontological kind did not affect word extension-children in both the animal and tool conditions chose on the basis of the only informative cue available on the trial (i.e. either shape or function). However, when there was a conflict between shape and function within the same trial, children emphasized function more when 
extending a novel word to artifacts than when extending a word to animals, as evidenced by their weighted scores for shape/function conflict trials. These findings suggest that four-year-olds' knowledge about animal and artifact categories led them to extend the novel label on the basis of the most relevant property for each category, given the information provided in the word learning situation. More specifically, children in the tool condition interpreted the function of 'holding a ball' as critical to the identity of the 'rompel', while children in the animal condition focused more on overall shape. Furthermore, these findings indicate that four-year-olds do not always attend to shape in a word learning context, as will be discussed further in the General discussion.

Another possibility, however, is that the eyes on the objects acted as an attentional flag. That is if, as Colunga \& Smith (2008) have argued, children have simply learned 'automatic' correlations between perceptual features, then no conceptual notion of animacy or artifacts is required to explain our findings. To address this possibility, we conducted a follow-up experiment in which we presented children with an object that had embodied perceptual cues to animacy (i.e. eyes), but was described as a tool. We expected that if children were using conceptual information to guide their decision-making, they would demonstrate the same pattern of lexical extension as children in the tool condition in Experiment $\mathbf{I}$.

\section{EXPERIMENT 2}

METHOD

\section{Participants}

Participants were 20 four-year-olds (ranging from $3 ; 9$ to $4 ; 5, M=4 ; 0$, $S D=2 \cdot 04$ months).

\section{Stimuli and procedure}

The stimuli and procedure were identical to Experiment I with two exceptions: first, all children were in the tool condition and second, the objects with eyes were described as tools using the same dialogue as in Experiment I.

\section{RESULTS AND DISCUSSION}

\section{Forced choice selections}

Results of the individual trials analyses appear in Table I. Chi-square analyses indicated that performance of children in the tool-eyes group did not differ from that of children in tool-no eyes group (Experiment I) 
PRESCHOOLERS'EXTENSION OF NOVEL WORDS

TAB LE 2. Description of weighted scoring scheme

\begin{tabular}{|c|c|c|c|c|}
\hline Trial type & Test object & presented & Score & Response type \\
\hline \multicolumn{5}{|l|}{ Function conflict $I$} \\
\hline & $\begin{array}{l}\text { Similar shape- } \\
\text { functional }\end{array}$ & $\begin{array}{l}\text { Similar shape- } \\
\text { non-functional }\end{array}$ & & \\
\hline \multirow[t]{3}{*}{ Extend label? } & Yes & No & $I \cdot O$ & Function \\
\hline & No & Yes & 0.5 & Inconsistent \\
\hline & Yes & Yes & 0.0 & Shape \\
\hline \multicolumn{5}{|l|}{ Function conflict 2} \\
\hline & $\begin{array}{l}\text { Dissimilar shape- } \\
\text { functional }\end{array}$ & $\begin{array}{l}\text { Dissimilar shape- } \\
\text { non-functional }\end{array}$ & & \\
\hline \multirow[t]{3}{*}{ Extend label? } & Yes & No & $I \cdot O$ & Function \\
\hline & No & Yes & 0.5 & Inconsistent/Null \\
\hline & Yes & Yes & 0.5 & Inconsistent/Null \\
\hline \multicolumn{5}{|l|}{ Shape conflict I } \\
\hline & $\begin{array}{l}\text { Similar shape- } \\
\text { functional }\end{array}$ & $\begin{array}{l}\text { Dissimilar shape- } \\
\text { functional }\end{array}$ & & \\
\hline Extend label? & Yes & Yes & $I \cdot O$ & Function \\
\hline & No & Yes & 0.5 & Inconsistent \\
\hline & Yes & No & 0.0 & Shape \\
\hline \multicolumn{5}{|l|}{ Shape conflict 2} \\
\hline & $\begin{array}{l}\text { Similar shape- } \\
\text { non-functional }\end{array}$ & $\begin{array}{l}\text { Dissimilar shape- } \\
\text { non-functional }\end{array}$ & & \\
\hline Extend label? & Yes & Yes & 0.5 & Inconsistent/Null \\
\hline & No & Yes & 0.5 & Inconsistent/Null \\
\hline & Yes & No & 0.0 & Shape \\
\hline \multicolumn{5}{|l|}{$\begin{array}{l}\text { Shape-function } \\
\text { conflict }\end{array}$} \\
\hline & $\begin{array}{l}\text { Similar shape- } \\
\text { non-functional }\end{array}$ & $\begin{array}{l}\text { Dissimilar shape- } \\
\text { functional }\end{array}$ & & \\
\hline \multirow[t]{3}{*}{ Extend label? } & No & Yes & $I \cdot O$ & Function \\
\hline & Yes & Yes & 0.5 & Inconsistent \\
\hline & Yes & No & 0.0 & Shape \\
\hline
\end{tabular}

( $p$ s $>0 \cdot 30)$. Consistent with the results of Experiment I, analyses comparing the tool group and the animal group from Experiment I indicated that object selections differed across groups only on the shape-function conflict trials. On these trials, the majority of children in the animal group chose the same shape-non-functional object as the referent of the novel word while the majority of children in tool-no eyes and tool-eyes groups chose the dissimilar shape-functional object $(p s<0 \cdot 0$ I $)$.

\section{Weighted choices}

Using the same scoring system as in Experiment I, we compared children's performance in the tool-eyes condition to that of the tool (no eyes) condition and the animal (eyes) condition using one-way ANOVAs. 
On the FUNCTION-CONFLICT TRIALS AND SHAPE-CONFLICT TRIALS, children in the tool-eyes condition did not differ significantly in their weighing of function from those in the tool-no eyes condition or the animal condition (all $p$ s $>0 \cdot 36$ ).

On the SHAPE-FUNCTION CONFLICT TRIALs, the ANOVA yielded a main effect of group $\left(F(2,8 \mathrm{I})=6 \cdot 73, \eta_{p}^{2}=0 \cdot \mathrm{I} 4, p<0 \cdot 0 \mathrm{I}\right)$. Follow-up comparisons using a Bonferroni correction indicated that children in the tool-eyes condition and in the tool-no eyes condition did not differ significantly in their weighted scores $(p>0.99)$. In contrast, children in the tool-eyes condition $(M=0.56, S D=0.27)$ weighed function significantly more than children in the animal condition $(M=0.38, S D=0.25 ; p<0.04)$.

Here four-year-olds in the tool-eyes conditions emphasized object function in their decisions to the same extent as children in the tool condition in Experiment I. Thus, even when the perceptual information suggested that the objects were animates, preschoolers attended to the conceptual information and treated these objects as if they were artifacts. These results are unexplainable through the ALA for the following reason: if children were only attending to the correlations between features of objects and their labels, the addition of embodied perceptual cues to animacy (i.e. eyes) should have overridden the effects of the description (i.e. tool) of the object. It is likely that children encounter new words in the context of animacy cues (e.g. eyes, self-motion) significantly more often than in the context of any particular descriptive label (i.e. tool or animal); therefore, if children were only attending to the correlations between words and objects, our results should have been reversed. Thus, consistent with the results from Booth \& Waxman (2002), four-year-olds' conceptual knowledge about artifact categories accounted for their differential performance in lexical extension, rather than their attention to perceptual correlations among features.

\section{GENERAL DISCUSSION}

We investigated the role of ontological kind in guiding children's differential attention to shape versus function for lexical extension. When extending a novel count noun to an artifact category (objects without eyes), four-yearolds interpreted the function of 'holding a ball' as critical for extension of the object label (Experiment I). When the object was described as an animal (objects with eyes), four-year-olds treated the object's shape as more central for lexical extension than its ability to hold a ball (Experiment I). However, when the same object with eyes was described as a tool, four-year-olds treated the object's function as more central than the object's shape (Experiment 2). These findings demonstrate that children treated function, as a cue to object identity, as more central to categories that are artifacts 
than overall shape. In contrast, children interpreted shape as a much better index of object kind than function for objects that were labeled as animates.

Our findings that four-year-olds rely on function, rather than shape, to extend novel count nouns to artifacts address a debate in the literature regarding the relative contribution of shape and function to object word extension. Studies have found that preschoolers extend novel words based on object shape rather than object function when these two properties are directly contrasted in word extension tasks (e.g. Gentner, I978; Smith, Jones \& Landau, I996). Even when function is emphasized as relevant for the lexical category, studies have found that preschoolers continue to rely primarily on shape for object word extension (e.g. Graham, Williams \& Huber, I999; Landau, Smith \& Jones, I 998). In contrast, other research has indicated that preschoolers will consider the functional affordance of an object when extending novel words when the function of the artifact is meaningful and tied to the object's design and children have had the opportunity to experience the test object's functions before generalizing the novel words (e.g. Kemler Nelson, I 999; Kemler Nelson, Frankenfield, Morris \& Blair, 2000). Our findings lend additional support to the notion that function can play an important role in lexical extension by indicating that when the function of the object is clearly tied to a part of the object and the object is clearly identified as a tool, children will consider the functional affordance of the object more relevant to the lexical category than its appearance.

Our findings support the view that children's conceptual knowledge or framework theories about animals and artifacts guide their naming decisions by four years of age (e.g. Barrett, Abdi, Murphy \& Gallagher, I 993 ; Booth \& Waxman, 2002; 2003). As such, the current findings address the debate in the literature regarding young children's early word learning. Consistent with recent research by Booth \& Waxman (2002) and Booth et al. (2005), our studies demonstrate that preschoolers will use conceptually based knowledge to guide their word extensions, and provide incremental evidence that the decision-making processes in word learning are likely guided by more than contextually based attentional mechanisms. A focus on perceptual properties alone cannot fully account for young children's performance in word learning, as our studies have shown that preschoolers will respond differently depending on the conceptual framework in which information is embedded, rather than on the basis of object appearance alone. This account is in direct contrast to the ALA view, in which one would be able to categorize and name objects appropriately without knowing anything about them beyond their appearance. We note that this richer interpretation of the mechanisms responsible for early word learning does not suggest that perceptual processes are unimportant in word 
learning or that preschoolers must have a complex, adult-like notion of ontological kind.

In conclusion, our findings indicate that explicitly providing information regarding the ontological kind of a novel object can have a profound influence on how preschoolers view that object, thereby providing insight into the power of conceptual information in guiding early word learning.

\section{REFERENCES}

Asher, Y. M. \& Kemler Nelson, D. G. (2008). Was it designed to do that? Children's focus on intended function in their conceptualization of artifacts. Developmental Psychology ro6, $474-83$.

Barrett, S. E., Abdi, H., Murphy, G. L. \& Gallagher, J. M. (I993). Theory-based correlations and their role in children's concepts. Child Development 64, I 595-6 I6.

Bloom, P. (2000). How children learn the meanings of words. Cambridge, MA: MIT Press.

Booth, A. E. \& Waxman, S. R. (2002). Word learning is 'smart': Evidence that conceptual information affects preschoolers' extension of novel words. Cognition 84, B I I-B22.

Booth, A. E. \& Waxman, S. R. (2003). Bringing theories of word learning in line with the evidence. Cognition 87, 2 I 5-I 8 .

Booth, A. E. \& Waxman, S. R. (2008). Taking stock as theories of word learning take shape. Developmental Science II, I 85-94.

Booth, A. E., Waxman, S. R. \& Huang, Y. T. (2005). Conceptual information permeates word learning in infancy. Developmental Psychology 4I, 49I-505.

Colunga, E. \& Smith, L. B. (2008). Knowledge embedded in process: The self-organization of skilled noun learning. Developmental Science II, I95-203.

Gelman, S. A. (2003). The essential child: Origins of essentialism in everyday thought. New York: Oxford University Press.

Gelman, S. A. \& Wellman, H. M. (I99I). Insides and essences: Early understandings of the non-obvious. Cognition 38, 2 I $3-44$.

Gentner, D. (1978). What looks like a jiggy but acts like a zimbo? A study of early word meaning using artificial objects. Papers and Reports on Child Language Development 15, I-6.

Graham, S. A., Williams, L. D. \& Huber, J. F. (I 999). Preschoolers' and adults' reliance on object shape and object function for lexical extension. Fournal of Experimental Child Psychology 74, I28-5 I.

Jones, S. S. \& Smith, L. B. (1998). How children name objects with shoes. Cognitive Development $\mathbf{1 3}, 323-34$.

Jones, S. S. \& Smith, L. B. (2002). How children know the relevant properties for generalizing object names. Developmental Science 5, $219-32$.

Kemler Nelson, D. G. (1999). Attention to functional properties in toddlers' naming and problem-solving. Cognitive Development I4, 77-1 о०.

Kemler Nelson, D. G., Frankenfield, A., Morris, C. \& Blair, E. (2000). Young children's use of functional information to categorize artifacts: Three factors that matter. Cognition 75, $\mathrm{I}-36$.

Landau, B., Smith, L. B. \& Jones, S. S. (I988). The importance of shape in early lexical learning. Cognitive Development 3, 299-32 I.

Landau, B., Smith, L. B. \& Jones, S. S. (I998). Object shape, object function, and object name. Fournal of Memory and Language $38,1-27$.

Rakison, D. H. \& Poulin-Dubois, D. (200I). Developmental origins of the animate-inanimate distinction. Psychological Bulletin 127, 209-228.

Samuelson, L. K. \& Smith, L. B. (I 999). Early noun vocabularies: Do ontology, category organization and syntax correspond? Cognition, 73, (I), I-33. 


\section{PRESCHOOLERS'EXTENSION OF NOVEL WORDS}

Samuelson, L. K. \& Smith, L. B. (2000). Children's attention to rigid and deformable shape in naming and nonnaming tasks. Child Development 71, I 555-70.

Smith, L. B., Jones, S. S. \& Landau, B. (1996). Naming in young children: A dumb attentional mechanism? Cognition 6o, I 43-7 I.

Smith, L. B. \& Samuelson, L. K. (2006). An attentional learning account of the shape bias: Reply to Cimpian and Markman (2005) and Booth, Waxman and Huang (2005). Developmental Psychology 42, I339-43. 